398

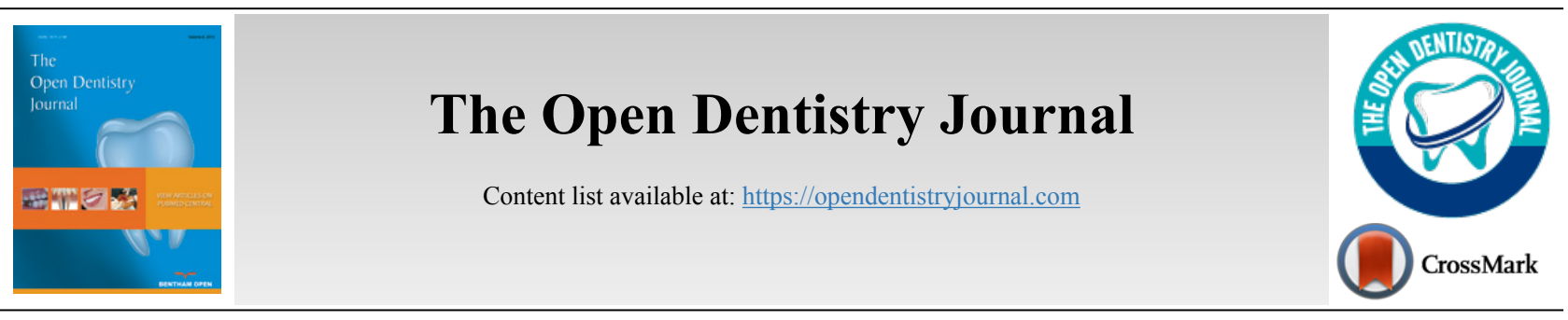

RESEARCH ARTICLE

\title{
Face Proportions, and Analysis of Maxillary Anterior Teeth and Facial Proportions in a Thai Population
}

\author{
Asikul Wadud ${ }^{1,2, *}$, Jira Kitisubkanchana ${ }^{3}$, Peerapong Santiwong ${ }^{4}$ and M.L. Theerathavaj Srithavaj ${ }^{1}$ \\ ${ }^{I}$ Department of Prosthodontics, Maxillofacial Prosthetic Service, Faculty of Dentistry, Mahidol University, Bangkok, Thailand \\ ${ }^{2}$ Department of Prosthodontics, Update Dental College and Hospital, Aichi Nagar, Turag, Dhaka, Bangladesh \\ ${ }^{3}$ Department of Oral and Maxillofacial Radiology, Faculty of Dentistry, Mahidol University, Bangkok, Thailand \\ ${ }^{4}$ Department of Orthodontics, Faculty of Dentistry, Mahidol University, Bangkok, Thailand
}

\begin{abstract}
:
Background:

Esthetics is the primary consideration for patients looking for prosthetic treatment. Determining the facial types of Thai populations is important because most studies conducted in Caucasian populations mention their facial types, and describe the gender comparisons, and GP of the teeth.

Objectives:

This study compared facial proportions, analyzed the maxillary anterior teeth proportions and determined the relationships between teeth with facial measurements using the Golden Proportion (GP) and Golden Standard (GS) in a Thai population.

\section{Methods:}

A total of 200 students (18-35 years) with well-aligned maxillary anterior teeth participated in this study. Face heights and widths were measured from the face using digital calipers and faces were classified as narrow, average, and broad. Teeth and face proportions were compared with GP and GS. One-way ANOVA was performed to compare maxillary anterior teeth proportions and facial proportions with different face types ( $\alpha=$ $0.05)$. Pearson's correlation was used $(\alpha=0.05)$ to determine the correlation between facial proportion and teeth dimension among different facial types.

Results:

The findings showed $82.50 \%$ narrow face, $13.50 \%$ average, and $4 \%$ broad face among Thai subjects. No GP or GS was found in the face and anterior teeth, but teeth and face proportions other than GP and GS were found. No significant correlation was found between the Width of the

Central Incisor (WCI) with interpupillary distance and alar width.

Conclusion:

In this study, the GP was not found in the facial and teeth proportion. The data obtained from this study may help to provide guidelines for prosthetic and orthodontic management and help to select the proper size and form of the maxillary anterior teeth to achieve proper esthetic outcomes in the Thai population.
\end{abstract}

Keywords: Facial types, Maxillary anterior teeth, Golden proportion, Thai, Gender comparisons, Facial landmarks.

\begin{tabular}{|l|l|l|r|}
\hline Article History & Received: October 1, 2020 & Revised: November 17, 2020 & Accepted: December 20, 2020
\end{tabular}

\section{INTRODUCTION}

Esthetics is the primary consideration for patients looking for prosthetic treatment. Facial landmarks are important to pro-

\footnotetext{
* Address correspondence to this author at the Department of Prosthodontics, Update Dental College and Hospital, Aichi Nagar, Turag, Dhaka 1711, Bangladesh; E-mail: asikul_wadud@hotmail.com
}

duce a pleasant facial harmony expression in estheticrestorations. The human face has a variety of shapes [1]. The facial esthetic evaluation has become an essential component for facial esthetics assessment, cosmetic dentistry, and reconstructive surgeries [2 - 4]. Maxillary central incisors play an important role in esthetics and are mostly seen from the front $[5-8]$. The importance of dental proportion with different 
facial types was emphasized by Lombardi et al. [9] and they found a recurring ratio noted between the face and the teeth from the central incisor to the first premolar. The facial index is a numerical expression of the ratio between the facial heights (nasion to menton), (NMH), and the bizygomatic width (BZW) of a living person $[4,10]$. Faces can be classified using a facial index. Usually, faces are classified into three types: broad, average, and narrow. Many studies have investigated the maxillary anterior teeth proportion with face types in various regions of the world.

Among the esthetic principles, the proportion can be predicted with a formula that defines the ratio of the component from one constituent to the next. The GP has been used from studying beauty to design esthetic restorations [11 13] and constitutes a valuable tool to evaluate symmetry, dominance, and proportion in diagnosing tooth arrangement and applying esthetic dental treatment [5]. Dental and facial aesthetics are optimized when the proportion between widths of the maxillary anterior teeth is repeated as the patient is viewed from the front [14]. In this manner, the visible WLI is $62 \%(0.618)$ of the central incisor and the visible width of the canine is $62 \%(0.618)$ of the lateral incisor $[6,15,16]$. Leven also mentioned that the ratio of $2 \mathrm{WCI}$ to the central incisor mean height (2WCI/HCI) is equal to the GP (1.618) [14]. The Golden Standard (GS) is the ratio of the actual width to height $(\mathrm{W} / \mathrm{H})$ of the maxillary central incisors; it should be $80 \%[17$, 18]. The anterior teeth with a higher $\mathrm{W} / \mathrm{H}$ ratio indicate short teeth, while a lower ratio indicates long teeth. The study conducted on GS suggested a range of 66 to $88 \%$ for GS for maxillary anterior teeth $[5,19]$. Facial types play an important role in prosthetic management in selecting artificial teeth especially anterior teeth.

Regarding teeth proportion, gender variations in the dimension of the anterior teeth have been noted in most racial groups with men and women. Men exhibit wider teeth than women [20 - 22]. Several anatomic measurements are used to identify the correct size and shape of anterior teeth in relation to the face. Intercommissural width, BZW, alar width, and interpupillary distance are mostly discussed [23 - 28].

Determining the facial types in a Thai population is important because most studies conducted in Caucasian populations mention their facial types and describe gender comparisons and the GP of the teeth. However, to our knowledge, no study has investigated the maxillary anterior teeth proportion in a Thai population. This study aimed to compare the anterior teeth proportion among three facial types and compare them with the GP.

\section{MATERIALS AND METHODS}

A total of 200 participants (67 males and 133 females) participated in this cross-sectional study using the criteria: (a) subject is willing to participate in the study, (b) age of the male and female participants is 18-35 years, (c) no missing maxillary anterior teeth, (d) no gingival or periodontal conditions or therapies (e) mild interdental spacing between anterior teeth, not more than $0.5 \mathrm{~mm}$, (f) minimal crowding as defined by Little's Irregularity Index (score of linear displacement of five anterior contact points of each of the maxillary anterior teeth from the adjacent teeth ranging from 1 to 3 ), (g) no anterior restoration, (h) no intruding or extruding anterior teeth, (i) no anterior open bite and (j) no apparent loss of tooth structure due to attrition, fracture or caries. The study protocol and ethics were approved by the Institutional Review Board of the Faculty of Dentistry, Mahidol University. All participants were requested to read the informed consent form and sign it before participating. Each participant was measured for BZW, face height $(\mathrm{NMH})$, alar width, and mouth width using digital calipers (Model CD 6, Mitutoyo Co., Kannagawa, Japan) (Fig. 2). The facial index was calculated using the BZW/facial height $(\mathrm{NMH})$ in percentage and the facial type was classified as broad, average, or narrow [29].

Then, irreversible hydrocolloid (Jeltrate, Dentsply, PA, USA) was used to make an impression of the maxillary arch from each participant and a dental cast was made using type IV dental stone (Vel-Mix stone, Kerr Co., CA, USA). All these materials were used according to the manufacturer's instructions. The perceived width of each anterior tooth was measured according to the method mentioned by Al-Marzok et al. [30] and Rokaya et al. [29]. For perceived width measurement using a plain paper, the first line was drawn and the cast was placed on that line to measure the perceived width of the six anterior teeth from the front side. The mesial and distal borders of the teeth were noted, and lines were drawn on the paper. Then, digital calipers were used to measure the distance between these lines to calculate the perceived width of the six anterior teeth. The mean perceived ratios of the central incisor to the lateral incisor and canine to the lateral incisor and the mean ratio of the width of 2 central incisors to the height of the central incisor were calculated. The mean results of $\mathrm{CI} / \mathrm{LI}$, $\mathrm{C} / \mathrm{LI}$, and $\mathrm{W} 2 \mathrm{CI} / \mathrm{HCI}$ in the total studied population were compared with the three facial types and with the GP. For the actual width of the anterior teeth measurement, maximum mesiodistal distance, and maximum vertical distance from the cervical margin to the incisal edge were measured from the cast. Then, the mean actual width to the height ratio $(\mathrm{W} / \mathrm{H})$ was determined. These ratios were calculated in percentages. The mean $\mathrm{W} / \mathrm{H}$ ratio was used to compare among the three facial types in the total studied population.

All the measurements were made by a single investigator. Each measurement was measured three times and mean values were calculated. Statistical Package for Social Science (SPSS 18.0 ) was used with the level of significance $(\alpha)=0.05$ for statistical analysis.

\section{RESULTS}

In all, 67 males and 133 females participated in this study. The 3 facial types classified included 8 broad faces (4\%), 27 average faces (13.5\%) and 165 narrow faces $(82.5 \%)$. In the male group, 6 broad, 12 average, and 49 narrow facial types were identified, and in the female group, 2 broad, 15 average, and 165 narrow facial types (Table 1). The facial types comprised broad 139.50 (2.95\%), average 130.40 (5.79\%) and narrow 124.25 (6.56\%); while the mean facial index was broad $81.90(1.72 \%)$, average $84.52(1.71 \%)$ and narrow 90.92 (2.83\%). Besides, significant differences were found in BZW and FI in 3 facial types $(p<0.05)$, while NMH showed 
significant differences only between average and narrow face types $(\mathrm{p}<0.05)$ (Table 2$)$.

The studied teeth proportion showed significant differences with GP and GS $(\mathrm{p}<0.05)$. The mean teeth proportion in the total population included CI/LI 1.29 (0.13), C/LI $0.71(0.08)$, W2CI/HCI 1.79 (0.11), CI W/H ratio 90.10 (5.39), LI W/H ratio $87.86(6.71)$ and $\mathrm{C} \mathrm{W} / \mathrm{H}$ ratio 88.89 (5.74). All the data showed significant differences with GP and GS. No GP and GS were found in the studied population, as shown in Table $\mathbf{3}$ and Fig. (1). W/H ratio of the central incisor, lateral incisor, and canine showed no significant difference among 3 face types except $\mathrm{W} / \mathrm{H}$ ratio between average and narrow face type $(\mathrm{p}<0.05)$ using One way ANOVA post-hoc: Gabriel Test as shown in Fig. (2).

Table 1. Distribution of facial types among males and females in the studied Thai population.

\begin{tabular}{|c|c|c|c|}
\hline \multirow{2}{*}{ Facial Type } & \multicolumn{3}{|c|}{ Gender } \\
\cline { 2 - 4 } & Male & Female & Total \\
\hline Broad & $6(3 \%)$ & $2(1 \%)$ & $27(13.5 \%)$ \\
\hline Average & $12(6 \%)$ & $15(7.5 \%)$ & $165(82.5 \%)$ \\
\hline Narrow & $49(24.5 \%)$ & $116(58 \%)$ & $200(100 \%)$ \\
\hline Total & $67(34 \%)$ & $133(66 \%)$ & \\
\hline
\end{tabular}

Table 2. Facial measurements and facial index in $\mathbf{3}$ face types.

\begin{tabular}{|c|c|c|c|c|c|c|}
\hline \multirow[t]{2}{*}{ Facial Measurement } & \multirow{2}{*}{$\begin{array}{c}\begin{array}{c}\text { Broad } \\
(\mathrm{n}=8)\end{array} \\
\begin{array}{c}\text { Mean } \\
(\mathrm{SD})\end{array} \\
\end{array}$} & \multirow{2}{*}{$\begin{array}{c}\begin{array}{c}\text { Average } \\
(\mathrm{n}=27)\end{array} \\
\text { Mean } \\
(\mathrm{SD})\end{array}$} & \multirow{2}{*}{$\begin{array}{c}\begin{array}{c}\text { Narrow } \\
(\mathrm{n}=165)\end{array} \\
\begin{array}{c}\text { Mean } \\
(\mathrm{SD})\end{array}\end{array}$} & \multicolumn{3}{|c|}{$\begin{array}{c}\mathrm{p} \text { value } \\
\text { (One-way ANOVA; post-hoc: Gabriel) }\end{array}$} \\
\hline & & & & Broad vs Average & Average $v s$ Narrow & Broad vs Narrow \\
\hline Bizygomatic width (BZW) & $\begin{array}{l}139.50 \\
(2.95) \\
\end{array}$ & $\begin{array}{l}130.40 \\
(5.79) \\
\end{array}$ & $\begin{array}{l}124.25 \\
(6.56) \\
\end{array}$ & $.001 *$ & $<.001 *$ & $<.001^{*}$ \\
\hline Nasion-menton (NMH) & $\begin{array}{l}114.28 \\
(3.86) \\
\end{array}$ & $\begin{array}{l}110.12 \\
(5.65)\end{array}$ & $\begin{array}{l}113.10 \\
(5.89)\end{array}$ & .182 & $<.05^{*}$ & .878 \\
\hline $\begin{array}{l}\text { Facial Index (FI): } \\
(\mathrm{NMH}: \mathrm{BZW})\end{array}$ & $\begin{array}{l}81.90 \\
(1.72)\end{array}$ & $\begin{array}{r}84.52 \\
(1.71)\end{array}$ & $\begin{array}{l}90.92 \\
(2.83)\end{array}$ & $.035 *$ & $<.001^{*}$ & $<.001 *$ \\
\hline
\end{tabular}

*Significant difference at $P<0.05$

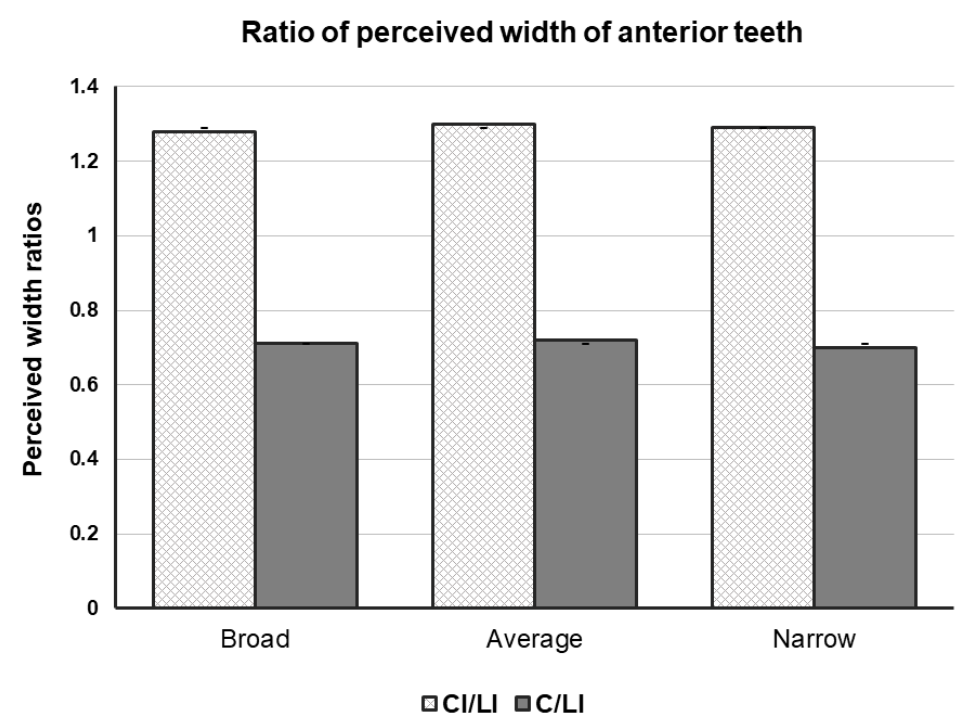

Fig. (1). Ratios of perceived widths of central incisors/lateral incisors and canine/lateral incisors in 3 facial types among Thai subjects. 


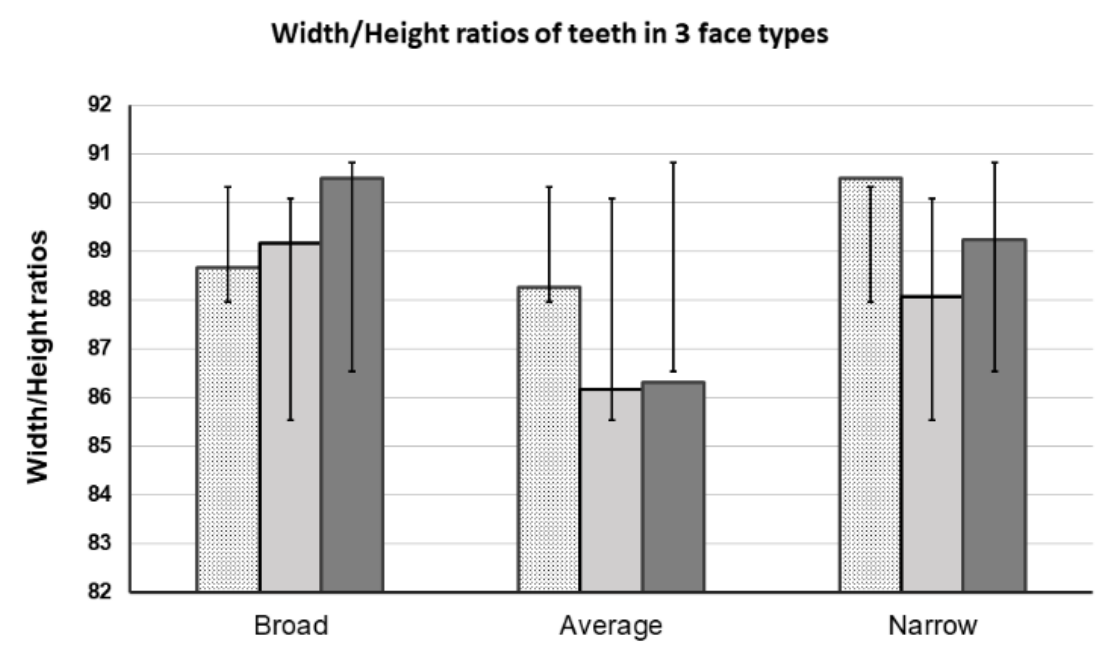

$\square$ W/H Cl $\quad$ 口W/H LI $\quad$ घW/H C

Fig. (2). Width to height ratio of the central incisor, lateral incisor, and canine among Thai subjects.

Table 3. Teeth proportion compared with GP and GFS in the total studied Thai population.

\begin{tabular}{|c|c|c|c|}
\hline \multirow{2}{*}{ Teeth Proportion } & \multicolumn{2}{|c|}{ Total studied Thai population (N=200) } \\
\cline { 2 - 4 } & Mean (SD) & \multicolumn{2}{c|}{$\begin{array}{c}\text { p value } \\
\text { (One-sample t-test with GP } \text { SL }_{\text {\& GS) }}\end{array}$} \\
\hline CI/LI & $1.29(0.13)$ & $<0.001^{*}$ & - \\
\hline C/LI & $0.71(0.08)$ & $<0.001^{*}$ & - \\
\hline W2CI/HCI & $1.79(0.11)$ & $<0.001^{*}$ & $<0.001^{*}$ \\
\hline CI W/H (\%) & $90.10(5.39)$ & - & $<0.001^{*}$ \\
\hline LI W/H (\%) & $87.86(6.71)$ & - & $<0.001^{*}$ \\
\hline C W/H (\%) & $88.89(5.74)$ & - & \\
\hline
\end{tabular}

\section{DISCUSSION}

The Thai population is genetically diverse due to its different ethnicities and historical background. All the participating dental students of this present study came from different provinces of the country, representing the diverse Thai population. In this study, direct facial measurements were made, and FI was used to classify the facial types in other studies [29, 31, 32]. The predominant facial type in this study was a narrow face followed by an average face and broad face. This finding is similar to a study conducted in a Turkish population (173 subjects) where they found that $37.58 \%$ had a narrow face, $34.10 \%$ had a broad face and $28.33 \%$ had an average face [31]. Another similar study was conducted in a Nepali population, which showed $11(7.33 \%)$ broad faces, 35 (23.33\%), average faces, and 104 (69.33\%) narrow faces [29]. A study conducted in a Bangladeshi population showed a narrow face was the most common facial type (56\%), followed by an average face (44\%) [33]. However, in their study, the broad face was not found. This all may indicate that a narrow face might be the most common facial type in Asian populations.
In this study, there was a significant difference in the BZW: IPD between broad and narrow, average, and narrow groups, because the BZW significantly differed between broad and average, average, and narrow and broad and narrow. A 3D electromagnetic study was conducted by Sforza et al. [34] to observe the size and form of faces of Italian adolescent boys and girls. Among all groups, a wider upper face than reference adolescents of the same age and sex was found; in both female groups and among young adolescent males significant differences were found. The maxilla was smaller among attractive girls than among their reference adolescents but larger among attractive boys relative to the mandible. Attractive adolescents had a smaller nose than reference subjects of the same age and sex. Ferrario et al. [35] found significant differences between television actresses and normal women while investigating the soft tissue facial landmarks. Larger foreheads, the larger middle third of the face, wider dimensions and deeper faces, smaller noses, and less facial convexity were observed in the television actress group. Longer lower one third and shorter upper two-thirds of the face were examined in the sample Thai population. The GP of the face was not found among normal people but was found in a 
special group of people who might have some history of surgical facial correction. According to other similar studies, no GP of the face was found in this study as we had excluded all kinds of esthetic facial correction in this research sample.

The neoclassical canon divides the face vertically into 5 equal spaces; all the studies conducted among white and Asian subjects used anthropometry and photogrammetric analyses, which manifested variations in these proportions, with the width of the eyes and nasal widths often being either less than or greater than the inner-canthi distance [36]. In this study, the vertical fifth of the face is equal in different types of faces except for the width of the eye on both sides showed significant differences in the average and narrow group and broad and narrow group. In addition, using the one-sample ttest, significant differences were found between the width of the nose and inner canthi distance, and between the width of the mouth and interpupillary distance $(\mathrm{p}<0.05)$.

In this present study, neither GP nor GS was found in teeth proportions similar to related studies $[11,18,29,30,33,37$ 39]. Beautiful smiles do not have these dental proportions, indicating some conflict with reality and the GP [38]. According to Mashid et al. [40] if we consider the occurrence of the GP in a broad range of 0.55 to 0.64 , we would find that the GP in the average group was $2.5 \%$ and in the narrow group was $4.5 \%$ for $\mathrm{CI} / \mathrm{LI}$ and, $0.5 \%$ in the broad group, $2.5 \%$ in the average group and $11 \%$ in the narrow group for $\mathrm{C} / \mathrm{LI}$. In the total studied population, GP was seen in $7 \%$ for $\mathrm{CI} / \mathrm{LI}$ and $14 \%$ for $\mathrm{C} / \mathrm{LI}$. Regarding W2CI/HCI ratios, no GP was found in all three groups suggesting that Thai populations have wider central incisors than in the WCI using the GP. Similarly, for Nepalese, the GP and GS percentage were not found, and the Nepalese Esthetic Dental (NED) proportion results in an esthetically pleasing smile $[29,41]$. The $\mathrm{W} / \mathrm{L}$ ratio for CI, LI, and $\mathrm{CN}$ was found to be $90,86,86 \%$, respectively, and a proportion of $66 \%$ for $\mathrm{LI} / \mathrm{CI}$ and $70 \%$ for $\mathrm{CN} / \mathrm{LI}$ were found. These can be used in the esthetic rehabilitation of the maxillary anterior teeth among Nepalese patients. In the present study, the obtained $\mathrm{W} / \mathrm{H}$ ratios $(90 \%$ for central incisor, $87 \%$ for the lateral incisor, and $88 \%$ for canine) could be helpful in clinical practice and in manufacturing artificial teeth.

Furthermore, the present study established a positive correlation between intercanine distance and intercanine tip distance with the BZW, interpupillary distance, nasal width, and mouth width, which was similar to the study conducted by Hasanreisoglu [32], where he found a positive correlation between the intercanine tip width and nasal width. Ellakwa $e t$ al. [42] found a weak positive correlation existed between intra-oral (WCI, canine to canine width) and extra-oral (intercanthal distance, interpupillary distance, interalar width, commissure of lip width) measurements that remained consistent when examined by gender. Similarly, al-El-Sheikh and al-Athel [43] in a Saudi population found a significant correlation between interalar, interpupillary and maxillary anterior teeth width for the entire sample and when the sample was divided by gender, correlation was found only among females. In our study, intercanine distance was $1 / 3.29$ of the BZW, whereas intercanine tip distance was $1 / 3.48$ of the BZW. These results were similar to the values given by Sears [44], reporting that the width of the total anterior teeth was $1 / 3.3$ of the BZW. The results of our study also showed a linear positive correlation between WCI with the BZW revealing that the WCI was $1 / 14.02$ of the BZW. This result was similar to the result obtained by Berry's biometric ratio method [45] and Pound's concept [46], where they proposed that the maxillary central incisor width was $1 / 16$ of the width of the face or BZW. In addition, the WCI was $1 / 4.02$ of the intercanine tip distance, $1 / 4.25$ of the intercanine distance, $1 / 6.29$ of the innerpupillary distance, $1 / 4.04$ of the nose width and 1/5.11 of the mouth width. Thus, this could be useful in calculating the WCI.

Finally, in this study, some negligible amount of inaccuracy could have occurred during all kinds of measurements and cast fabrications.

\section{CONCLUSION}

Among the studied Thai subjects, $82.50 \%$ represented a narrow face, $13.50 \%$ represented average and $4 \%$ represented a broad face. No GP or GS was found compared with the 6 maxillary anterior teeth in the studied population. Anterior teeth measurements with different facial landmarks showed a significant correlation. However, no significant correlation was found in the WCI with interpupillary distance and alar width $(p<0.05)$. The $\mathrm{W} / \mathrm{H}$ ratio of central incisor, lateral incisor, and canine showed no significant difference with 3 face types except $\mathrm{W} / \mathrm{H}$ ratios between average and narrow face types $(p<.05)$. The size and shape of the maxillary anterior teeth were the most important factors to achieve pleasing dental and facial esthetics. The data obtained from this study may help to provide guidelines for prosthetic management with proper esthetic outcomes in Thai populations according to their facial proportions.

\section{AUTHOR'S CONTRIBUTIONS}

Dr. Asikul Wadud, Dr. M.L. Theerathavaj Srithavaj, and Dr. Amornrat Wonglamsam designed the research. Dr. Asikul Wadud performed the research, analyzed the data, and prepared the manuscript. Dr. M.L. Theerathavaj Srithavaj and Dr. Amornrat Wonglamsam supervised the research. Dr. Asikul Wadud analyzed the data. Dr. Jira Kitisubkanchana, Dr. Peerapong Santiwong, Dr. M.L. Theerathavaj Srithavaj, and Dr. Amornrat Wonglamsam reviewed the manuscript and gave an opinion.

\section{ETHICS APPROVAL AND CONSENT TO PARTI- CIPATE}

This study received approval from the Institutional Review Board of the Faculty of Dentistry, Mahidol University, Bangkok, Thailand.

\section{HUMAN AND ANIMAL RIGHTS}

No animals were used in this research. All human research procedures followed were in accordance with the ethical standards of the committee responsible for human experimentation (institutional and national), and with the Helsinki Declaration of 1975, as revised in 2013. 


\section{CONSENT FOR PUBLICATION}

All participants signed the consent before participating in the study.

\section{AVAILABILITY OF DATA AND MATERIALS}

The authors confirm that the data supporting the findings of this research are available within the article.

\section{FUNDING}

None.

\section{CONFLICT OF INTEREST}

The authors declare they have no conflict of interest, financial or otherwise.

\section{ACKNOWLEDGEMENTS}

The authors would like to thank Associate Professor Nita Viwattanatipa, Associate Professor Amornrat Wonglamsam, Assistant Professor Sita Thaworanunta, Dr. Arunee Tirasriwat, Dr. Pokpong Amorvit, Dr. Dinesh Rokaya, Dr. Natdanai Chotprasert, Dr. Binit Shrestha, Dr. Ongart Puttipisitchet, Dr. Ornnicha Pooktuantong, and Phuangpaka Somtan, students and staff of Faculty of Dentistry, Mahidol University for their guidance and support in the conduct of this research. This research was supported by the Graduate Studies and Department of Prosthodontics, Faculty of Dentistry, Mahidol University, Thailand 10400, Thailand.

\section{REFERENCES}

[1] Naini FB, Gill DS. Facial aesthetics: 1. Concepts and canons. Dent Update 2008; 35(2): 102-104, 106-107. [http://dx.doi.org/10.12968/denu.2008.35.2.102] [PMID: 18426163]

[2] Fortes HN, Guimarães TC, Belo IM, da Matta EN. Photometric analysis of esthetically pleasant and unpleasant facial profile. Dental Press J Orthod 2014; 19(2): 66-75.

[http://dx.doi.org/10.1590/2176-9451.19.2.066-075.oar] [PMID: 24945516]

[3] Rokaya D, Bhattarai B, Suttagul K, Kafle D, Humagain M. Mentolabial sulcus: An esthetic-based classification. J Datta Meghe Inst Med Sci Univ 2018; 13(1): 16-9.

[http://dx.doi.org/10.4103/jdmimsu.jdmimsu 80 17]

[4] Sundareswaran S, Ramakrishnan R. The Facial Aesthetic index: An additional tool for assessing treatment need. J Orthod Sci 2016; 5(2): 57-63.

[http://dx.doi.org/10.4103/2278-0203.179409] [PMID: 27127752]

[5] Brisman AS. Esthetics: A comparison of dentists' and patients' concepts. J Am Dent Assoc 1980; 100(3): 345-52. [http://dx.doi.org/10.14219/jada.archive.1980.0093] [PMID: 6928165]

[6] Marquardt SR. Dr. Stephen R. Marquardt on the Golden Decagon and human facial beauty. Interview by Dr. Gottlieb. J Clin Orthod 2002; 36(6): 339-47. [PMID: 12101544]

[7] Humagain M, Rokaya D, Srii R, Dixit S, Kafle D. Gender based comparison of gingival zenith esthetics. Kathmandu Univ Med J (KUMJ) 2016; 14(54): 148-52. [KUMJ].

[PMID: 28166072]

[8] Guragain M, Mathema S, Rokaya D. Evaluation of fracture resistance and sites of failure of different dowel core restorations: An in-vitro study. Open Dent J 2019; 13: 454-61.

[http://dx.doi.org/10.2174/1874210601913010454]

[9] Lombardi RE. The principles of visual perception and their clinical application to denture esthetics. J Prosthet Dent 1973; 29(4): 358-82. [http://dx.doi.org/10.1016/S0022-3913(73)80013-7] [PMID: 4570911]

[10] Diomande M, Beugre J-B, Koueita MKK, Vaysse F. Relationship between angular measurements and facial shape of young Ivorians with normal dental occlusion. Sci World J 2018; 20186395910 [http://dx.doi.org/10.1155/2018/6395910] [PMID: 29681778]

[11] Ali Fayyad M, Jamani KD, Agrabawi J. Geometric and mathematical proportions and their relations to maxillary anterior teeth. J Contemp Dent Pract 2006; 7(5): 62-70.

[http://dx.doi.org/10.5005/jcdp-7-5-62] [PMID: 17091141]

[12] Murthy BV, Ramani N. Evaluation of natural smile: Golden proportion, RED or Golden percentage. J Conserv Dent 2008; 11(1): 16-21.

[http://dx.doi.org/10.4103/0972-0707.43413] [PMID: 20142879]

[13] Al-Saleh SA, Al-Shammery DA, Al-Shehri NA, Al-Madi EM. Awareness of dental esthetic standards among dental students and professionals. Clin Cosmet Investig Dent 2019; 11: 373-82.

[http://dx.doi.org/10.2147/CCIDE.S224400] [PMID: 31819659]

[14] Levin EI. Dental esthetics and the golden proportion. J Prosthet Dent 1978; 40(3): 244-52.

[http://dx.doi.org/10.1016/0022-3913(78)90028-8] [PMID: 279670]

[15] Qualtrough AJ, Burke FJ. A look at dental esthetics. Quintessence Int 1994; 25(1): 7-14

[PMID: 8190886$]$

[16] Ricketts RM. The biologic significance of the divine proportion and Fibonacci series. Am J Orthod 1982; 81(5): 351-70. [http://dx.doi.org/10.1016/0002-9416(82)90073-2] [PMID: 6960724]

[17] Morley J, Eubank J. Macroesthetic elements of smile design. J Am Dent Assoc 2001; 132(1): 39-45.

[http://dx.doi.org/10.14219/jada.archive.2001.0023] 11194397]

[18] Pini NP, de-Marchi LM, Gribel BF, Ubaldini AL, Pascotto RC. Analysis of the golden proportion and width/height ratios of maxillary anterior dentition in patients with lateral incisor agenesis. J Esthet Restor Dent 2012; 24(6): 402-14.

[http://dx.doi.org/10.1111/j.1708-8240.2012.00533.x] [PMID: 23205688]

[19] Snow SR. Esthetic smile analysis of maxillary anterior tooth width: The golden percentage. J Esthet Dent 1999; 11(4): 177-84. [http://dx.doi.org/10.1111/j.1708-8240.1999.tb00397.x] [PMID: 10825874]

[20] Gillen RJ, Schwartz RS, Hilton TJ, Evans DB. An analysis of selected normative tooth proportions. Int J Prosthodont 1994; 7(5): 410-7. [PMID: 7802908]

[21] Sterrett JD, Oliver T, Robinson F, Fortson W, Knaak B, Russell CM. Width/length ratios of normal clinical crowns of the maxillary anterior dentition in man. J Clin Periodontol 1999; 26(3): 153-7. [http://dx.doi.org/10.1034/j.1600-051X.1999.260304.x] [PMID: 10100040]

[22] Owens EG, Goodacre CJ, Loh PL, et al. A multicenter interracial study of facial appearance. Part 2: A comparison of intraoral parameters. Int J Prosthodont 2002; 15(3): 283-8. [PMID: 12066492]

[23] Scandrett FR, Kerber PE, Umrigar ZR. A clinical evaluation of techniques to determine the combined width of the maxillary anterior teeth and the maxillary central incisor. J Prosthet Dent 1982; 48(1): $15-22$.

[http://dx.doi.org/10.1016/0022-3913(82)90041-5] [PMID: 6955504]

[24] Cesario VA Jr, Latta GH Jr. Relationship between the mesiodistal width of the maxillary central incisor and interpupillary distance. J Prosthet Dent 1984; 52(5): 641-3.

[http://dx.doi.org/10.1016/0022-3913(84)90133-1] [PMID: 6593457]

[25] Hoffman W Jr, Bomberg TJ, Hatch RA. Interalar width as a guide in denture tooth selection. J Prosthet Dent 1986; 55(2): 219-21. [http://dx.doi.org/10.1016/0022-3913(86)90348-3] [PMID: 3514860]

[26] Latta GH Jr, Weaver JR, Conkin JE. The relationship between the width of the mouth, interalar width, bizygomatic width, and interpupillary distance in edentulous patients. J Prosthet Dent 1991; 65(2): $250-4$

[http://dx.doi.org/10.1016/0022-3913(91)90170-2] [PMID: 2051360]

[27] Rokaya D, Suttagul K, Maharjan SK, Sapkota B. Gender based comparison of the relationships of maxillary anterior teeth and facial measurements. J Int Dent Medical Res 2018; 14(54): 148-52.

[28] Abdullah MA. Inner canthal distance and geometric progression as a predictor of maxillary central incisor width. J Prosthet Dent 2002; 88(1): 16-20

[http://dx.doi.org/10.1067/mpr.2002.126095] [PMID: 12239474]

[29] Rokaya D, Kitisubkanchana J, Wonglamsam A, Santiwong P, Srithavaj T, Humagain M. Nepalese esthetic dental (NED) proportion in Nepalese population. Kathmandu Univ Med J (KUMJ) 2015; 13(51): 244-9. [KUMJ].

[http://dx.doi.org/10.3126/kumj.v13i3.16816] [PMID: 27180372] 
[30] Al-Marzok MI, Majeed KRA, Ibrahim IK. Evaluation of maxillary anterior teeth and their relation to the golden proportion in Malaysian population. BMC Oral Health 2013; 13: 9-9.

[http://dx.doi.org/10.1186/1472-6831-13-9] [PMID: 23347800]

[31] Arslan SG, Genc C, Odabas B, Kama JD. Comparison of facial proportions and anthropometric norms among Turkish young adults with different face types. Aesthetic Plast Surg 2008; 32(2): 234-42. [http://dx.doi.org/10.1007/s00266-007-9049-y] [PMID: 17952492]

[32] Hasanreisoglu U, Berksun S, Aras K, Arslan I. An analysis of maxillary anterior teeth: Facial and dental proportions. J Prosthet Dent 2005; 94(6): 530-8.

[http://dx.doi.org/10.1016/j.prosdent.2005.10.007] [PMID: 16316799]

[33] Jamayet NB, Viwattanatipa N, Amornvit P, Pornprasertsuk S, Chindasombatjaroen J, Alam MK. Comparison of crown width/length ratio of six maxillary anterior teeth between different facial groups in Bangladeshi population. Int Med J 2014; 21: 49-54.

[34] Sforza C, Laino A, D'Alessio R, Grandi G, Catti F, Ferrario VF. Three-dimensional facial morphometry of attractive adolescent boys and girls. Prog Orthod 2007; 8(2): 268-81.

[PMID: 18030373]

[35] Ferrario VF, Sforza C, Poggio CE, Tartaglia G. Facial morphometry of television actresses compared with normal women. J Oral Maxillofac Surg 1995; 53(9): 1008-14.

[http://dx.doi.org/10.1016/0278-2391(95)90115-9] [PMID: 7643270]

[36] Sim RS, Smith JD, Chan AS. Comparison of the aesthetic facial proportions of southern Chinese and white women. Arch Facial Plast Surg 2000; 2(2): 113-20.

[http://dx.doi.org/10.1001/archfaci.2.2.113] [PMID: 10925436]

[37] Forster A, Velez R, Antal M, Nagy K. Width ratios in the anterior maxillary region in a Hungarian population: addition to the golden proportion debate. J Prosthet Dent 2013; 110(3): 211-5.

[http://dx.doi.org/10.1016/S0022-3913(13)60359-5]

[PMID:
[38] Rosenstiel SF, Ward DH, Rashid RG. Dentists' preferences of anterior tooth proportion--a web-based study. J Prosthodont 2000; 9(3): 123-36.

[http://dx.doi.org/10.1053/jopr.2000.19987] [PMID: 11179463]

[39] Melo M, Ata-Ali F, Huertas J, et al. Revisiting the maxillary teeth in 384 subjects reveals a deviation from the classical aesthetic dimensions. Sci Rep 2019; 9(1): 730

[http://dx.doi.org/10.1038/s41598-018-36770-w] [PMID: 30679534]

[40] Mahshid M, Khoshvaghti A, Varshosaz M, Vallaei N. Evaluation of "golden proportion" in individuals with an esthetic smile. J Esthet Restor Dent 2004; 16(3): 185-92.

[http://dx.doi.org/10.1111/j.1708-8240.2004.tb00032.x] [PMID: 15597640]

[41] Rokaya D, Humagain M, Amornvit P. Maxillary anterior teeth proportions for creating esthetically pleasuring smile in Nepalese patients. J Nepal Health Res Counc 2018; 16(3): 362.

[http://dx.doi.org/10.33314/jnhrc.v16i3.1672] [PMID: 30455503]

[42] Ellakwa A, McNamara K, Sandhu J, et al. Quantifying the selection of maxillary anterior teeth using intraoral and extraoral anatomical landmarks. J Contemp Dent Pract 2011; 12(6): 414-21.

[http://dx.doi.org/10.5005/jp-journals-10024-1069] [PMID: 22269230]

[43] al-el-Sheikh HM, al-Athel MS. The relationship of interalar width, interpupillary width and maxillary anterior teeth width in Saudi population. Odontostomatol Trop 1998; 21(84): 7-10. [PMID: 11372110]

[44] Sears VH. An analysis of art factors in full denture construction. J Amer Dent Assoc Dent Cosmos 1938; 25(1): 3-12.

[http://dx.doi.org/10.14219/jada.archive.1938.0028]

[45] Berry FH. Is the theory of temperaments the foundation of the study of prosthetic art? Dent Mag 1905; 1: 405-13.

[46] Pound E. Lost - fine arts in the fallacy of the ridges. J Prosthet Dent 1954; 4: 6-16.

[http://dx.doi.org/10.1016/0022-3913(54)90060-8]

\section{2021 Wadud et al.}

This is an open access article distributed under the terms of the Creative Commons Attribution 4.0 International Public License (CC-BY 4.0), a copy of which is available at: https://creativecommons.org/licenses/by/4.0/legalcode. This license permits unrestricted use, distribution, and reproduction in any medium, provided the original author and source are credited. 